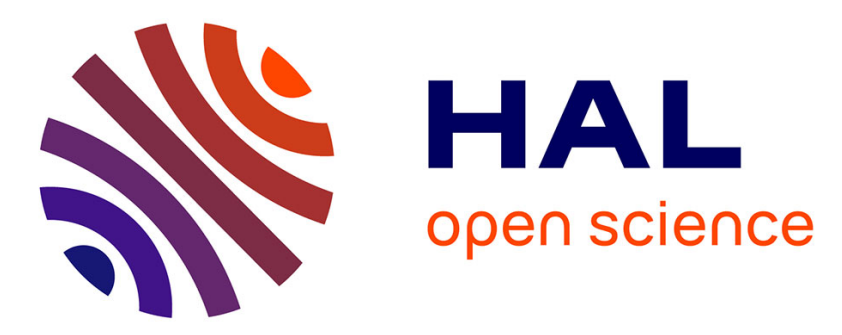

\title{
Application of 3C-SiC quantum dots for living cell imaging
}

J. Botsoa, V. Lysenko, Alain Geloen, O. Marty, J. Bluet, G. Guillot

\section{To cite this version:}

J. Botsoa, V. Lysenko, Alain Geloen, O. Marty, J. Bluet, et al.. Application of 3C-SiC quantum dots for living cell imaging. Applied Physics Letters, 2008, 92 (17), 10.1063/1.2919731 . hal-01928805

\section{HAL Id: hal-01928805 https://hal.science/hal-01928805}

Submitted on 30 Nov 2018

HAL is a multi-disciplinary open access archive for the deposit and dissemination of scientific research documents, whether they are published or not. The documents may come from teaching and research institutions in France or abroad, or from public or private research centers.
L'archive ouverte pluridisciplinaire $\mathbf{H A L}$, est destinée au dépôt et à la diffusion de documents scientifiques de niveau recherche, publiés ou non, émanant des établissements d'enseignement et de recherche français ou étrangers, des laboratoires publics ou privés. 


\section{Application of $3 C-\mathrm{SiC}$ quantum dots for living cell imaging}

J. Botsoa, V. Lysenko, A. Géloën, O. Marty, J. M. Bluet, and G. Guillot

Citation: Appl. Phys. Lett. 92, 173902 (2008); doi: 10.1063/1.2919731

View online: https://doi.org/10.1063/1.2919731

View Table of Contents: http://aip.scitation.org/toc/apl/92/17

Published by the American Institute of Physics

\section{Articles you may be interested in}

Fabrication and photoluminescence of $\mathrm{SiC}$ quantum dots stemming from $3 \mathrm{C}, 6 \mathrm{H}$, and $4 \mathrm{H}$ polytypes of bulk $\mathrm{SiC}$ Applied Physics Letters 101, 131906 (2012); 10.1063/1.4755778

The absorption of oxygenated silicon carbide nanoparticles

The Journal of Chemical Physics 133, 064705 (2010); 10.1063/1.3464482

Influence of the interfacial chemical environment on the luminescence of $3 \mathrm{C} \square \mathrm{SiC}$ nanoparticles

Journal of Applied Physics 107, 013503 (2010); 10.1063/1.3273498

Luminescence from colloidal 3C-SiC nanocrystals in different solvents

Applied Physics Letters 88, 041909 (2006); 10.1063/1.2168018

Photon absorption and emission properties of $7 \AA$ SiC nanoclusters: Electronic gap, surface state, and quantum size effect

Applied Physics Letters 109, 013104 (2016); 10.1063/1.4955125

Room-temperature near-infrared silicon carbide nanocrystalline emitters based on optically aligned spin defects Applied Physics Letters 105, 243112 (2014); 10.1063/1.4904807

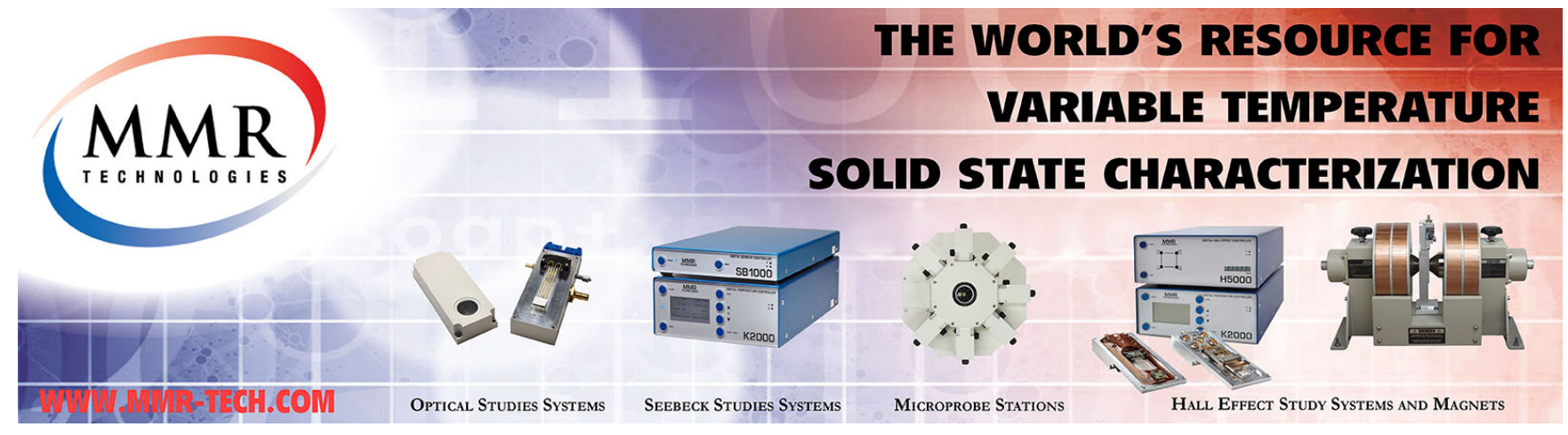




\title{
Application of $3 C$-SiC quantum dots for living cell imaging
}

\author{
J. Botsoa, ${ }^{1, a)}$ V. Lysenko, ${ }^{1}$ A. Géloën, ${ }^{2}$ O. Marty, ${ }^{3}$ J. M. Bluet, ${ }^{1}$ and G. Guillot ${ }^{1}$ \\ ${ }^{1}$ Institut des Nanotechnologies de Lyon (INL), CNRS UMR 5270, INSA de Lyon, Villeurbanne F-69621, \\ France \\ ${ }^{2}$ INSERM, U-870, F-69008, INRA, U1235, F-69008, INSA de Lyon, RMND, F-69621, Université Lyon 1, \\ Hospices Civils de Lyon, 69003 Lyon, France \\ ${ }^{3}$ Institut des Nanotechnologies de Lyon (INL), CNRS UMR 5270, Université Lyon 1, Villeurbanne F-69622, \\ France
}

(Received 21 March 2008; accepted 14 April 2008; published online 2 May 2008)

\begin{abstract}
Highly luminescent, stable, and biocompatible 3C-SiC quantum dots (QDs) with no protective shells have been applied for fluorescence imaging of biological living cells. Structural and luminescent properties of the 3C-SiC QDs are described. Marking of the living cells with such QDs highlights the penetration, accumulation, and heterogeneous distribution of the QDs inside the intracellular space. (C) 2008 American Institute of Physics. [DOI: 10.1063/1.2919731]
\end{abstract}

Fluorescence microscopy has allowed the functional study of various molecules that have been identified in living cells. The capabilities of this technique have generated a huge interest in developing new probes for tagging molecules and observing changes in their cellular concentrations and activities. ${ }^{1}$ Quantum dots (QDs) based on II-VI (e.g., $\mathrm{CdSe}, \mathrm{CdTe}, \mathrm{CdS}$, and $\mathrm{ZnSe}$ ) and III-V (e.g., InP and InAs) semiconductors have attracted considerable scientific interest over the past two decades due to their remarkable luminescent properties which are not found in either isolated molecules or bulk solids. ${ }^{2}$ Recent research efforts were particularly oriented toward applications of the semiconductor QDs as fluorescent probes in the biomedical field. ${ }^{3}$ Compared to organic dyes and fluorescent proteins, the semiconductor QDs are known to offer several unique advantages such as size- and composition-induced tunable emission, high quantum yield, and low photobleaching. However, the widely used II-VI semiconductors QDs were found to be cytotoxic through the release of free metallic ions (cadmium ions for instance). ${ }^{4-6}$ Therefore, a protective shell ( $\mathrm{ZnS}$ or a polymer, for example) must be systematically added. In this respect, natural biocompatible surface coatings such as peptides ${ }^{7}$ or sugars ${ }^{8}$ can be less nocuous to cells than any other artificial shell. However, no protective shell can guarantee an efficient chemical isolation of the extremely toxic luminescent core of the II-VI based QDs from the living cell environment. Today, it becomes clear that the cytotoxicity strongly influencing biological cell functioning is one of the major limiting factors for the application of II-VI QDs in efficient living cell imaging. In order to completely avoid this problem, one has to use QDs based on biocompatible materials.

In this letter, we report the application of highly luminescent, biocompatible (hence containing no specific protection), hydrophilic QDs based on silicon carbide ( $\mathrm{SiC}$ ) for biological cell imaging.

Indeed, bulk $\mathrm{SiC}$ is known to be a chemically inert, stable, and biocompatible material. In particular, the SiC biocompatibility at macroscopic scale has been proven by several research teams and allowed numerous interesting biomedical applications of this material. ${ }^{9,10}$ In addition, $\mathrm{Wu}$ and co-workers have recently reported on intense photolumines-

${ }^{a)}$ Electronic mail: jacques.botsoa@insa-lyon.fr. cence (PL) in the visible spectral range of $\mathrm{SiC}$ nanoparticles with cubic symmetry (3C-SiC) diluted in various liquid solutions. ${ }^{11,12}$ Moreover, after a storage in air for more than 7 months, the $3 C$-SiC QDs were shown to still be uniformly dispersed in aqueous solution and to maintain their remarkable luminescent properties. ${ }^{13}$

In our work, $3 C$-SiC nanoparticles were formed by means of electrochemical anodization of a low resistivity grade $(<1 \Omega$.cm) bulk $3 C$-SiC polycrystalline wafer. The etching process took place for $3 \mathrm{~h}$ under UV illumination at a current density of $25 \mathrm{~mA} / \mathrm{cm}^{2}$ using a $1: 1 \mathrm{HF}(50 \%) /$ ethanol electrolyte. After the etching, a highly porous network constituted by interconnected $3 C$-SiC nanocrystals was formed. The ultraporous layer was then naturally dried in ambient air and then removed from the wafer. The $3 C$-SiC nanopowder obtained by dry grinding of the formed free nanoporous layer was then dispersed in Krebs buffer solution. The formed suspension was centrifuged at $5000 \mathrm{~g}$ for $3 \mathrm{~min}$ in order to sediment large crystallites at the bottom of the centrifugation vials and to collect the useful top part of the suspension containing only very small $(<10 \mathrm{~nm})$ and uniformly dispersed nanoparticles.

Transmission electron microscopy (TEM) was used to observe the $3 C$-SiC nanoparticles constituting the aqueous colloidal suspension. Toward this end, the nanoparticles were deposited on a graphite grid by evaporation of a part of the colloidal nanosuspension. Figure 1(a) shows a TEM image of the spherical-like nanocrystallites. The lattice fringes seen on a high-resolution TEM image of a single QD given in Fig. 1(b) correspond to the interatomic planes of $3 C$-SiC. Size distribution over about $3003 C$-SiC nanoparticles visible on the TEM image from Fig. 1(a) is presented in Fig. 1(c). As one can see, all the QD dimensions are found below $4 \mathrm{~nm}$ with the maximum size probability being around $1.6 \mathrm{~nm}$. These QDs with dimensions smaller than the Bohr diameter of the exciton $(\sim 5.4 \mathrm{~nm})$ in bulk $\mathrm{SiC}$, may then exhibit highly efficient above-gap luminescence due to quantum confinement. An example of a daylight photo of the centrifuged optically homogeneous colloidal suspension of the $3 C$-SiC QDs used in our work is given in Fig. 1(d). The observed yellow color is ensured by a combined optical effect of (i) scattering on the suspended nanoparticles, (ii) absorption by the colloidal nanosuspension, as well as (iii) 

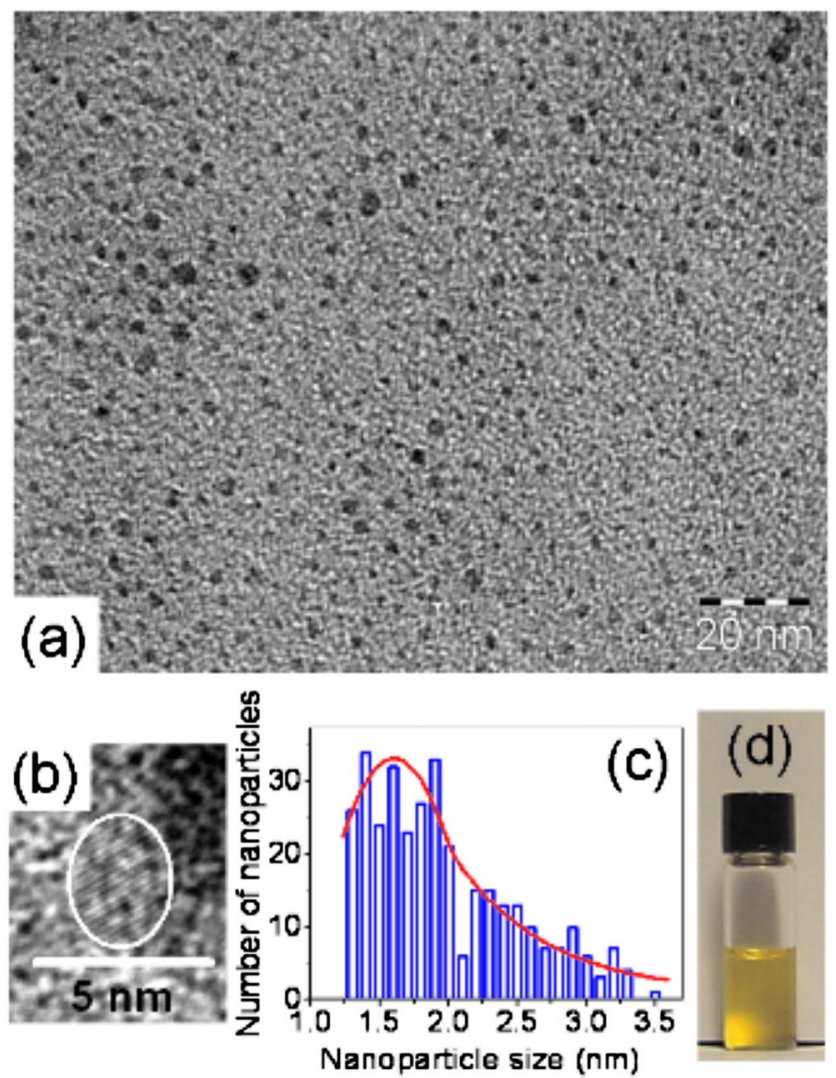

FIG. 1. (Color online) (a) TEM image of the $3 C$-SiC QDs, (b) highresolution TEM image of a single $3 C$ - $\mathrm{SiC}$ QD (c) size distribution diagram of the $3 C$-SiC QDs, and (d) daylight image of $3 C$-SiC QD suspension in aqueous buffer solution.

room temperature fluorescence of the suspended $3 C$-SiC QDs.

Figure 2(a) shows the absorption spectrum of the colloidal 3C-SiC QDs. There is a soft absorption edge below the bulk $3 C$-SiC band gap and a strong continuous rise in absorbance above the band gap until around $3.2 \mathrm{eV}$ where a plateau is reached. Below the band gap, the QDs can absorb light via band tail states. The above band gap absorption is due to band-band transitions in different-sized QDs. Indeed, according to the quantum confinement model, the smaller the QD is, the larger is its electronic band gap. Hence, the detected continuous rise in the absorbance upon the increase in the incident photon energy is due to absorption by a growing number of QDs with band gaps lower than the incident photons. The absorbance signal plateau is reached when the smallest nanoparticles in the solution are excited.
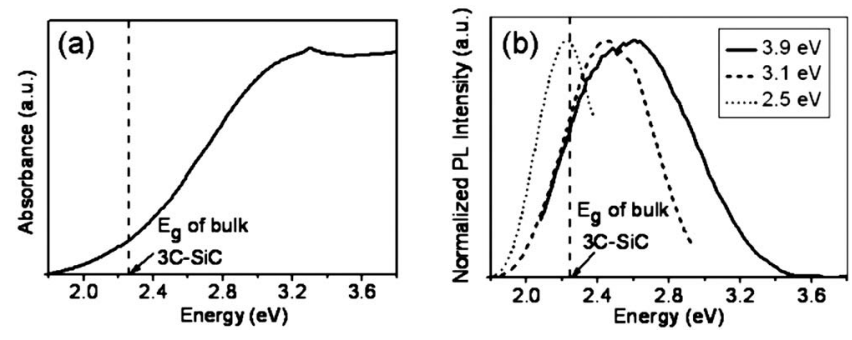

FIG. 2. (a) Absorption spectrum of the colloidal 3C-SiC QDs, (b) normalized room temperature PL spectra of a colloidal suspension containing $3 C$-SiC QDs acquired at three different excitation energies (2.5, 3.1, and $3.9 \mathrm{eV})$.
Figure 2(b) shows normalized PL spectra of the $3 C$-SiC QDs suspended in the Krebs buffer solution at three different excitation energies. The reduction of the excitation energy from 3.9 down to $2.5 \mathrm{eV}$ leads to the narrowing and redshift of the PL peak. This observed behavior is in good agreement with absorption measurements discussed above and with the quantum confinement model explaining radiative band-band transitions of the photoexcited charge carriers inside the $3 C$-SiC QDs. ${ }^{11-14}$ Indeed, for the $3.9 \mathrm{eV}$ excitation energy, which is higher than the band gap of the smallest QDs present in the suspension, the QDs of all dimensions (corresponding to a large band gap distribution) are photoexcited. Upon decreasing the excitation energy, only larger and larger QDs are excited resulting in narrower and redshifted PL spectra until the absorption by the largest $3 C$-SiC QDs is reached at $2.5 \mathrm{eV}$. At this stage, the emission is very close to the bulk $3 C$-SiC one.

The highly fluorescent suspension described above was added to cell cultures of 3T3-L1 fibroblasts (American Type Culture Collection, Manassas, VA, USA). The cells were grown in Dulbecco's modified Eagle's medium supplemented with $10 \%$ newborn calf serum, $4 \mathrm{mM}$ glutamine, $4 \mathrm{nM}$ insulin (Actrapid Human; Novo), $10 \mathrm{mM}$ Hepes, $25 \mu \mathrm{g}$ sodium ascorbate, $100 \mathrm{IU}$ penicillin, $100 \mu \mathrm{g}$ streptomycin, and $0.25 \mathrm{mg} / 1$ amphotericin $\mathrm{B}$ at $37{ }^{\circ} \mathrm{C}$ in a water saturated atmosphere with $5 \% \mathrm{CO} 2$ in air, in a Heraeus incubator (BB16). The cells were incubated overnight (for about $15 \mathrm{~h}$ ) in the presence of the $3 C$-SiC QDs (with concentrations ranging from to 0.1 to $2 \mathrm{~g} / 1$ ) dispersed in Krebs bicarbonate buffer $(p \mathrm{H}=7.4)$. After the incubation period and before their observation, the cells were rinsed twice in Krebs buffer to eliminate the QDs from their external environment. The fluorescence of the cell cultures with and without the QDs were observed by means of a fluorescence microscope (Leica DMI 4000B) with the following filter combination: $\mathrm{UV} /$ violet excitation $(2.92-3.5 \mathrm{eV})$ with an observation spectral range $<2.64 \mathrm{eV}$.

The photos in Fig. 3 highlight the incorporation of the fluorescent $3 C$-SiC QDs inside the biological cells. Indeed, under the UV/violet excitation, the cells marked by the QDs are very bright while the autofluorescence of unmarked cells is not visible at all. Comparison between the fluorescence micrographs and the microscope photos obtained under white light demonstrates that the fluorescing QDs are strongly localized inside the cells. Indeed, one can easily notice a heterogeneous distribution of the fluorescence intensity inside the cell. Since the highest intensities correspond to the position of the nuclei, it means that the QDs penetrated into the cells and preferentially concentrated at the nuclei. However, the question still remains whether the QDs entered the nucleus or are just concentrated on the outside of the nucleus membrane.

The magnified fluorescence photo in Fig. 4 showing two single cells marked by the $3 C$-SiC QDs confirms that the QDs are indeed strongly localized in the intracellular environment with brighter areas in the nucleus indicating that the QDs crossed the nucleus membrane. We can speculate that the penetration and accumulation of the QDs into the nucleus could be due to different mechanisms: (i) some specific transport system not yet clearly identified by which the nanoparticles are conveyed from the cytoplasm into the nucleus, (ii) bonding of the nanoparticles with some molecules which are involved in the intense traffic across the nucleus mem- 


\section{Without QDs | With QDs}

(a)

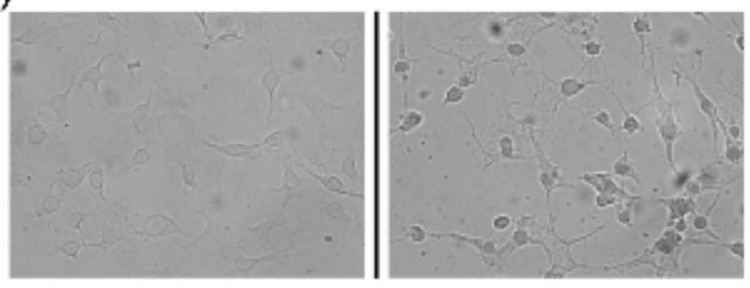

(b)

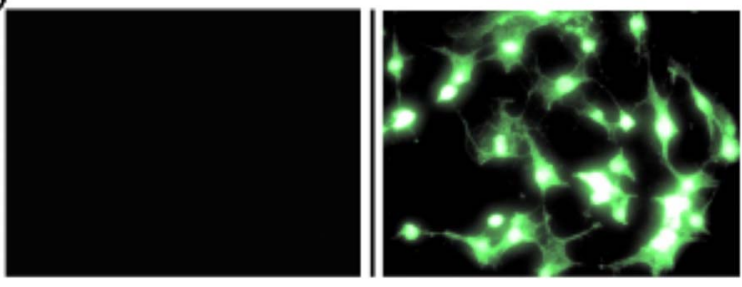

FIG. 3. (Color online) (a) White light microscopy images $(100 \times$ magnification) of biological cells not having been exposed to QDs (left column) and having been exposed to QDs (right column). (b) Corresponding fluorescence photos $(100 \times$ magnification) obtained under UV/violet excitation with the same accumulation times of $2 \mathrm{~s}$.

brane, or (iii) strong electrostatic interactions between charged nanoparticles and charged biomolecules inside the nucleus. The brighter areas suggest that $3 C$-SiC QDs could have been preferentially fixed on certain locations, for example, on heterochromatin. A detailed study of this important point will be performed in the nearest future by means of highly resolved observation techniques. Figure 4 also highlights a heterogeneous distribution of the QDs in the cytoplasm. In particular, we can notice a cytoskeletal-like structure in the cytoplasm.

Finally, fluorescence experiments have been done one week after intake of nanoparticles in the cell and the cells were found to still be living.

In conclusion, application of fluorescent 3C-SiC QDs for living cell imaging was shown. Penetration, accumulation, and heterogeneous distribution of the bare QDs in the intracellular environment were highlighted. The main advantage of the elaborated 3C-SiC QDs, over conventionally used QDs based on II-VI semiconductors is, of course, the noncytotoxicity for in vitro analysis and their potential biocompatibility for in vivo studies.

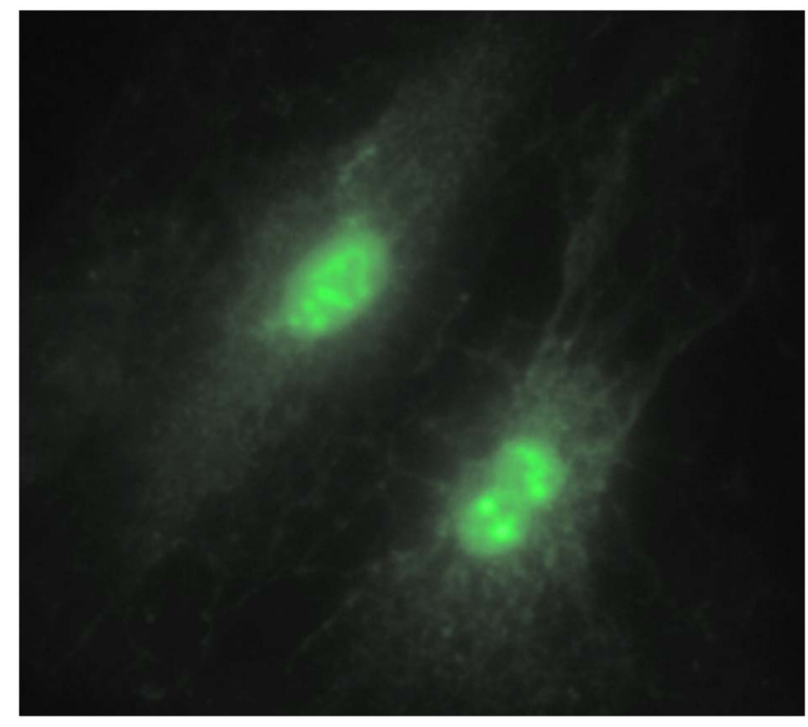

FIG. 4. (Color online) Fluorescence microphoto ( $200 \times$ magnification) of two single cells containing the $3 C$-SiC QDs.

This work was completely supported by INSA de Lyon within the frame of BQR-2006 research project. The authors acknowledge Dr. P. Pittet and Dr. B. Canut from University of Lyon 1 for their helpful technical support with the fluorescence imaging and absorption measurements, respectively.

${ }^{1}$ A. Miyawaki, A. Sawano, and T. Kogure, Nat. Cell Biol. 5, S1 (2003).

${ }^{2}$ A. P. Alivisatos, Science 271, 933 (1996).

${ }^{3}$ F. Pinaud, X. Michalet, L. A. Bentolila, J. M. Tsay, S. Doose, J. J. Li, G. Iyer, and S. Weiss, Biomaterials 27, 1679 (2006).

${ }^{4}$ A. M. Derfus, W. C. W. Chan, and S. N. Bhatia, Nano Lett. 4, 11 (2004).

${ }^{5}$ A. Hoshino, K. Fujioka, T. Oku, M. Suga, Y. F. Sasaki, T. Ohta, M. Yasuhara, K. Suzuki, and K. Yamamoto, Nano Lett. 4, 2163 (2004).

${ }^{6}$ C. Kirchner, T. Liedl, S. Kudera, T. Pellegrino, A. M. Javier, H. E. Gaub, S. Stolzle, N. Fertig, and W. J. Parak, Nano Lett. 5, 331 (2005).

${ }^{7}$ F. Pinaud, D. King, H. P. Moore, and S. Weiss, J. Am. Chem. Soc. 126, 6115 (2004).

${ }^{8}$ F. Osaki, T. Kanamori, S. Sando, T. Sera, and Y. Aoyama, J. Am. Chem. Soc. 126, 6520 (2004).

${ }^{9}$ R. Yakimova, R. M. Petoral, Jr., G. R. Yazdi, C. Vahlberg, A. Lloyd Spetz, and K. Uvdal, J. Phys. D 40, 6435 (2007), and references therein.

${ }^{10} \mathrm{H}$. Song and Z. Zhang, Mater. Sci. Eng., A 426, 59 (2006).

${ }^{11}$ X. L. Wu, J. Y. Fan, T. Qiu, X. Yang, G. G. Siu, and P. K. Chu, Phys. Rev. Lett. 94, 026102 (2005)

${ }^{12}$ J. Y. Fan, X. Wu, H. Li, H. Liu, G. G. Siu, and P. K. Chu, Appl. Phys. Lett. 88, 041909 (2006).

${ }^{13}$ J. Y. Fan, X. L. Wu, and P. K. Chu, Prog. Mater. Sci. 8, 983 (2006).

${ }^{14}$ J. Y. Fan, X. L. Wu, P. Q. Zhao, and P. K. Chu, Phys. Lett. A 360, 336 (2006). 